\title{
Ptosis after glaucoma surgery
}

This article was published in the following Dove Press journal:

Clinical Ophthalmology

14 August 2017

Number of times this article has been viewed

\author{
Abraham J Park' \\ Babak Eliassi-Rad ${ }^{2}$ \\ Manishi A Desai² \\ 'Moyes Eye Center, Department \\ of Ophthalmology, ${ }^{2}$ Boston \\ Medical Center, Department of \\ Ophthalmology, Boston, MA, USA
}

Purpose: Evaluate factors contributing to ptosis after glaucoma surgery.

Methods: Three-year retrospective chart review from January 1, 2012, to January 1, 2015, 157 eyes, 3 surgeons, at Boston Medical Center, to determine the incidence of ptosis and the effects of each variable contributing to ptosis at 3 months after surgery. Each variable was analyzed using the chi-square or independent samples $t$-test analysis to determine statistical significance of ptosis compared with above variables.

Results: The $t$-test or chi-square analysis showed that gender, steroid duration, use of mitomycin $\mathrm{C}$, duration of surgery, and prior surgeries were not statistically significant factors for ptosis. There was a statistically significant association between those $<70$ years of age and ptosis $(P<0.05)$, non-combined surgery and ptosis $(P<0.05)$, shunting surgery and ptosis $(P<0.05)$. Conclusion: Ptotic changes occurred more often in those who have shunting (Ahmed and Baerveldt) surgeries compared with filtering (trabeculectomy and Express) surgeries.

Keywords: ptosis, trabeculectomy, shunting surgery, filtering surgery, glaucoma, combined surgery

\section{Introduction}

Ptosis is a noted complication after eye surgery that can lead to cosmetic and functional defects. ${ }^{1}$ Its incidence has been documented to be around $10 \%$ after cataract surgery in previous studies ${ }^{1-4}$ while others have shown it to be as high as $44 \%$ at 6 weeks, although most resolve without treatment. ${ }^{5-7}$ Radial keratotomy has shown a rate of $10 \%$, and trabeculectomy has shown a rate of $10.7 \%-12 \%$ without mitomycin $\mathrm{C}$ (MMC) and 19\% with MMC 6 months after surgery. ${ }^{8}$ The incidence of ptosis following trabeculectomy was not influenced by type of conjunctival flap, combined surgery, or previous intraocular surgery. ${ }^{9}$

Some of the proposed mechanism behind the cause of ptosis after surgery include lid edema from locally administered anesthetic, initial myotoxic effects, and the compression of the upper eyelid against the orbital bones from the eyelid speculum reducing blood flow to the levator muscle contributing to the edema. ${ }^{1,2,10}$ However, another study showed the rates of ptosis after cataract surgery were common in both local and general anesthesia groups. ${ }^{11}$ Another theory is that the use of a lid speculum, stiffness of the lid speculum, and smaller palpebral fissures may play a greater role. ${ }^{3,5,12}$ Crosby et $\mathrm{al}^{12}$ have shown that the type of lid speculum can also affect the patients' eyelids during surgery with the greatest compression forces on those with the smallest palpebral apertures.

In this study, we investigated whether shunting procedures, duration of surgery, or use of steroids contributed to ptosis after surgery. We also re-evaluated the relationship of age, race, gender, use of MMC, type of speculum, number of previous eye surgeries, and combined glaucoma and cataract surgery to ptosis. 


\section{Methods}

A retrospective chart review was performed, with Institutional Review Board ( Integrated Network for Subject Protection In Research [INSPIR II] at Boston University Medical Campus and Boston Medical Center) approval, of a total of 252 eyes that underwent surgery between January 1, 2012, and January 1, 2015, at Boston Medical Center by one of three different surgeons. Diagnosis included angle recession, aphakic, chronic angle closure, mixed mechanism, normal or low tension glaucoma, ocular hypertension, pigment dispersion glaucoma, primary open angle glaucoma, pseudoexfoliation glaucoma, and uveitic glaucoma. Surgeries included shunting (Ahmed and Baerveldt) and filtering (fornix-based trabeculectomy and Express) surgery, either stand-alone (non-combined surgery) or with cataract surgery (combined surgery). The incidence of ptosis was determined by documented involvement of ptosis $>3$ months. Therefore, inclusion criteria included those 18-99 years of age with the diagnosis of primary and secondary glaucoma as listed above, and the persistent documentation of "ptosis" 3 months after glaucoma surgery. The exclusion criteria included inadequate documentation, previous history of ptosis, additional surgery within 3 months of primary glaucoma surgery, lack or lost to follow-up. The initial 252 eyes were reduced to 157 eyes after the exclusion criteria was applied. Due to the categorical nature of each variable, statistical analysis was performed using chi-square analysis or $t$-test analysis, when appropriate, to determine the statistical significance of variables on ptosis.

\section{Results}

\section{Background data}

The total number of eyes with ptosis was 27 (17.2\%) and the average time for a case with and without ptosis was 81.44 and 79.82 minutes, respectively. Time of surgery did not show statistical significance $(P=0.794)$. The number of females and males were 79 and 78, respectively. The number of left and right eyes were 80 and 77, respectively. Neither gender nor left or right eye was clinically significant for ptosis ( $P=0.307$ and $P=0.170$, respectively). About $90 \%$ of patients were in the 50-90 years age group and those $<70$ years of age showed clinical significance for ptosis $(P<0.05$, moderate relationship, Cramer's $V=0.20$ ). Out of 157 eyes, the type of speculum was only documented in 50 eyes and no clinically significant data could be determined $(P=0.069)$. MMC was exclusively used in 20 trabeculectomy cases, and they did not show any clinically significant data in relation to ptosis $(P=0.122)$. Steroid duration was split into categories of $<4,<8,<12$, and $>12$ weeks and did not show clinical significance for ptosis $(P=0.753)$. Fifty-seven eyes had prior
Table I Patient demographics

\begin{tabular}{llll}
\hline Demographics & & & \\
\hline Variables & No ptosis (\%) & Ptosis (\%) & P-value \\
\hline $\begin{array}{l}\text { Age } \\
\text { Mean }\end{array}$ & $67.23 \pm 12.76$ & $64.11 \pm 13.14$ & - \\
$\begin{array}{l}\text { Gender } \\
\text { Male }\end{array}$ & $63(79.7)$ & $16(20.3)$ & 0.31 \\
$\quad$ Female & $67(85.9)$ & $11(14.1)$ & \\
Eye & & & 0.17 \\
Left & $63(78.8)$ & $17(21.3)$ & \\
Right & $67(87.0)$ & $10(13.0)$ & \\
Ptosis & & $130(82.8)$ & \\
No & & $27(17.2)$ & \\
Yes & &
\end{tabular}

surgery with no clinical significance for ptosis $(P=0.598)$. Forty-six combined cases and 111 non-combined cases were clinically significant for ptosis in those undergoing glaucoma surgery alone (ie, without combined surgery) $(P<0.05$, weak-moderate relationship, Phi $=0.18)$. Sixty-eight shunting surgeries and 89 filtering surgeries showed clinically significant data for having increased ptosis, being greater in those with shunting surgery over filtering surgery $(P<0.05$, weak relationship, Phi $=0.16)$. General demographic data and relation to ptosis is summarized in Tables 1 and 2 .

In summary, variables that showed no clinical significance included gender, operated eye, steroid duration, use of MMC,

Table 2 Variables for ptosis

\begin{tabular}{|c|c|c|c|}
\hline Variables & No ptosis (\%) & Ptosis (\%) & $P$-value \\
\hline Surgical time & & & 0.79 \\
\hline Mean & $79.82 \pm 29.50$ & $81.44 \pm 28.42$ & \\
\hline Duration of steroid & & & 0.75 \\
\hline$<4$ weeks & $7(77.8)$ & $2(22.2)$ & \\
\hline$<8$ weeks & $58(86.6)$ & $9(13.4)$ & \\
\hline$<12$ weeks & $49(80.3)$ & $12(19.7)$ & \\
\hline$>12$ weeks & $16(80.0)$ & $4(20.0)$ & \\
\hline Type of speculum & & & 0.07 \\
\hline Lieberman & $5(83.3)$ & I (I6.7) & \\
\hline Netland & $12(94.4)$ & I (5.6) & \\
\hline Wire & $17(65.4)$ & $9(34.6)$ & \\
\hline Mitomycin C & & & 0.12 \\
\hline No & III (8I.0) & $26(19.0)$ & \\
\hline Yes & $19(95.0)$ & I (5.0) & \\
\hline Prior surgery & & & 0.60 \\
\hline No & $84(84.0)$ & $16(16.0)$ & \\
\hline Yes & $46(80.7)$ & II (19.3) & \\
\hline Combined surgery & & & 0.02 \\
\hline No & 87 (78.4) & $24(21.6)$ & \\
\hline Yes & $43(93.5)$ & $3(6.5)$ & \\
\hline Type of surgery & & & 0.04 \\
\hline Filtering* & $61(89.7)$ & $7(10.3)$ & \\
\hline Shunting** & $69(77.5)$ & $20(22.5)$ & \\
\hline
\end{tabular}

Notes: *Filtering surgery includes trabeculectomy and Express. **Shunting surgery includes Ahmed and Baerveldt. 
prior surgeries, and duration of surgery. The type of speculum could not be analyzed due to lack of documentation. Age, non-combined surgery, and type of surgery did show clinical significance for ptosis and will be discussed further.

\section{Age}

Due to the small number of patients $<50$ and $>80$ years of age, new categories were created to perform a chi-square test. New age groups were categorized into $<60$ years of age, 60-69 years of age, 70-79 years of age, and $>80$ years of age. Under the new categories, a chi-square test of independence was calculated by comparing the frequency of ptosis at 3 months after surgery for individuals in various age categories. Results showed that there was an association between age and ptosis at 3 months after surgery $\left(\chi^{2}(3)=8.04, \mathrm{~N}=157\right.$, $P \leq 0.05$ ). About $94 \%$ of $70-79$-year-old patients did not have ptosis, compared with $74 \%-82 \%$ of the rest of the age groups. The relationship was moderate in strength (Cramer's $V=0.23$; Table 3). As expected, the trend of those with prior surgeries were older $(68.6 \pm 12.4$ years of age) compared with those without prior surgery $(65.6 \pm 13.5$ years of age) but did not show statistical significance. As noted before, prior surgery did not show a statistically significant relationship with ptosis.

\section{Combined surgery}

A chi-square test of independence was calculated by comparing the frequency of ptosis at 3 months for those who

Table 3 Relationship between age categories and ptosis

\begin{tabular}{|c|c|c|c|c|}
\hline \multirow[t]{2}{*}{ Age category } & \multicolumn{3}{|c|}{ Ptosis (3 months) } & \multirow[t]{2}{*}{ Total } \\
\hline & \multicolumn{2}{|l|}{ No (\%) } & Yes (\%) & \\
\hline$<60$ years of age & $30(76.9)$ & \multicolumn{2}{|c|}{$9(23.1)$} & 39 \\
\hline $60-69$ years of age & $32(74.4)$ & \multicolumn{2}{|c|}{ II (25.6) } & 43 \\
\hline $70-79$ years of age & $50(94.3)$ & \multicolumn{2}{|c|}{$3(5.7)$} & 53 \\
\hline$>80$ years of age & I8 (8I.8) & \multicolumn{2}{|c|}{$4(18.2)$} & 22 \\
\hline Total & 130 & \multicolumn{2}{|c|}{27} & 157 \\
\hline \multicolumn{5}{|l|}{ Chi-square test $^{\prime}$} \\
\hline & Value & $d f$ & \multicolumn{2}{|c|}{$\begin{array}{l}\text { Asymptotic } \\
\text { significance(2-sided) }\end{array}$} \\
\hline Pearson chi-square & $8.038 *$ & 3 & 0.045 & \\
\hline Likelihood ratio & 9.170 & 3 & 0.027 & \\
\hline Linear-by-linear association & 2.798 & I & 0.094 & \\
\hline $\mathrm{N}$ of valid cases & 157 & & & \\
\hline \multicolumn{5}{|l|}{ Symmetric measures ${ }^{2}$} \\
\hline & \multicolumn{3}{|c|}{ Value } & $P<0.05$ \\
\hline Phi & \multicolumn{3}{|c|}{0.226} & 0.045 \\
\hline Cramer's V & \multicolumn{3}{|c|}{0.226} & 0.045 \\
\hline $\mathrm{N}$ of valid cases & \multicolumn{3}{|c|}{157} & \\
\hline
\end{tabular}

Notes: *I cell (12.5\%) have expected count $<5$. The minimum expected count is 3.78. 'Chi-square test: statistical method assessing the relationship between observed and expected categorical values. ${ }^{2}$ Symmetric measures determine strength of relationship between the observed and expected categorical values. did and did not have combined surgery. Results showed that there was a statistically significant association between non-combined surgery and having ptosis at 3 months after surgery $\left(\chi^{2}(1)=5.21, \mathrm{~N}=157, P<0.05\right)$. Results show that $78 \%$ of those who did not have combined surgery and $94 \%$ of those who had combined surgery did not develop ptosis. The relationship is weak to moderate in strength $(\mathrm{Phi}=0.18)$. Individuals who had combined surgery were less likely to develop ptosis (Table 4). If patients with prior surgery were excluded, the results were similar $\left(\chi^{2}(1)=5.30, \mathrm{~N}=100\right.$, $P<0.05)$ with an even stronger, moderate relationship (Phi $=0.23$; Table 3).

As expected, those who had prior surgery were much less likely to have a combined surgery. Of the 57 eyes that had prior surgery, only 1 had combined surgery. A chi-square test of independence showed a statistically significant association between those who did not have combined surgery and those who had prior surgery $\left(\chi^{2}(1)=32.78, \mathrm{~N}=157, P<0.05\right)$. There was a strong relationship $(\mathrm{Phi}=0.46)$. Those who were in the $>70$ years age group were also more likely to have combined surgery. About $45 \%$ of the people in the $>70$ years age group had combined surgery compared with $8 \%$ in the $<60$ years age group and $21 \%$ in the $60-69$ years age group. A chi-square test of independence showed a statistically significant association between older age and combined surgery $\left(\chi^{2}(2)=19.55, \mathrm{~N}=157, P \leq 0.05\right)$ with a strong relationship (Cramer's V=0.35).

Table 4 Relationship between non-combined surgery and ptosis

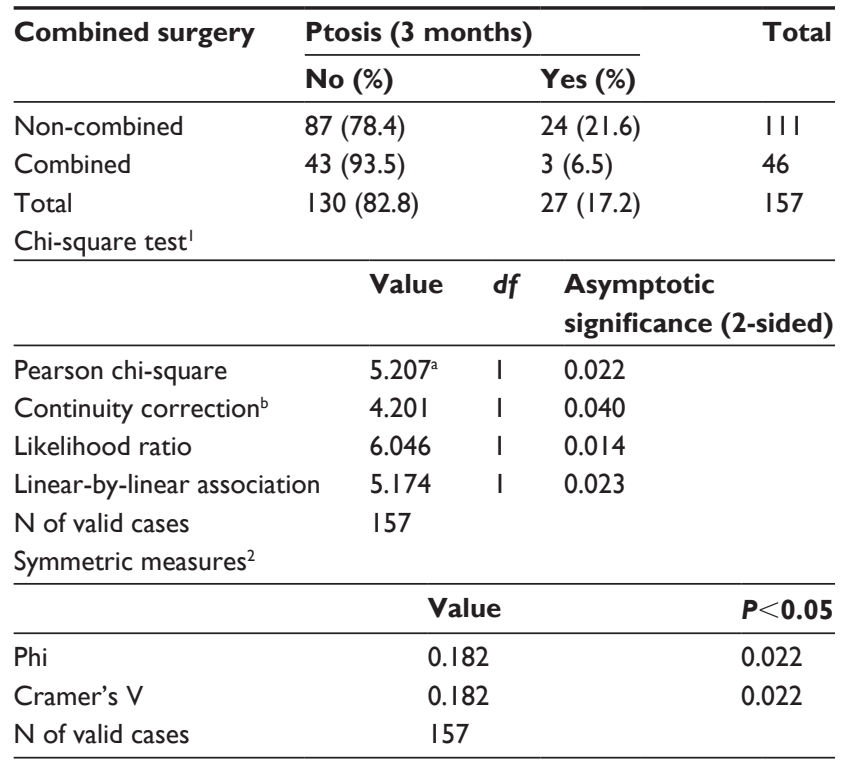

Notes: ${ }^{\mathrm{a}} 0$ cells $(0.0 \%)$ have expected count $<5$. The minimum expected count is

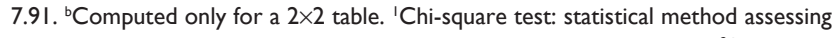
the relationship between observed and expected categorical values. ${ }^{2}$ Symmetric measures determine strength of relationship between the observed and expected categorical values. 


\section{Type of surgery}

A chi-square test of independence was calculated comparing the frequency of ptosis at 3 months after surgery for those who had a filtering surgery compared with shunting surgery. There was a statistically significant association between shunting surgery and ptosis 3 months after surgery $\left(\chi^{2}(1)=4.01\right.$, $\mathrm{N}=157, P<0.05)$. Ptosis developed in $10 \%$ of filtering surgery compared with $23 \%$ of shunting surgery. Shunting surgeries with Ahmed and Baerveldt were more likely to develop ptosis. Evidence shows a weak relationship ( $\mathrm{Phi}=0.16$; Table 5).

Further investigation revealed a relationship between non-combined surgery and shunting surgery. A chi-square test of independence results showed that there is a statistically significant association between shunting surgeries and non-combined surgery $\left(\chi^{2}(1)=8.17, \mathrm{~N}=157, P<0.01\right)$. This is a moderately strong relationship ( $\mathrm{Phi}=0.23$ ) (Table 6). Our results show that $64 \%$ of those without combined surgery were more likely to have a shunting surgery compared with $39 \%$ of those that did have a combined surgery. Additionally, there was no noted difference in age group and type of surgery performed (Table 7). The current result of this study shows that non-combined surgery and shunting surgery had a statistically significant relationship with ptosis and this relationship may strengthen the association between shunting surgery

Table 5 Relationship between type of surgery (shunting or filtering) and ptosis

\begin{tabular}{|c|c|c|c|}
\hline \multirow[t]{2}{*}{ Type of surgery } & \multicolumn{2}{|c|}{ Ptosis (3 months) } & \multirow[t]{2}{*}{ Total } \\
\hline & No (\%) & Yes (\%) & \\
\hline Shunting* & $61(89.7)$ & $7(10.3)$ & 68 \\
\hline Filtering** & $69(77.5)$ & $20(22.5)$ & 89 \\
\hline Total & 130 (82.8) & 27 (17.2) & 157 \\
\hline \multicolumn{4}{|l|}{ Chi-square test ${ }^{\prime}$} \\
\hline & Value & $d f$ & $\begin{array}{l}\text { Asymptotic } \\
\text { significance } \\
\text { (2-sided) }\end{array}$ \\
\hline Pearson chi-square & $4.014^{a}$ & I & 0.045 \\
\hline Continuity correction ${ }^{\mathrm{b}}$ & 3.205 & I & 0.073 \\
\hline Likelihood ratio & 4.202 & I & 0.040 \\
\hline Linear-by-linear association & 3.989 & I & 0.046 \\
\hline $\mathrm{N}$ of valid cases & 157 & & \\
\hline \multicolumn{4}{|l|}{ Symmetric measures ${ }^{2}$} \\
\hline & Value & & $P<0.05$ \\
\hline Phi & 0.160 & & 0.045 \\
\hline Cramer's V & 0.160 & & 0.045 \\
\hline $\mathrm{N}$ of valid cases & 157 & & \\
\hline \multicolumn{4}{|c|}{$\begin{array}{l}\text { Notes: *Shunting surgery includes Baerveldt and Ahmed implants. }{ }^{* *} \text { Filtering surgery } \\
\text { includes trabeculectomy and Express. }{ }^{a} 0 \text { cells }(0.0 \%) \text { have expected count }<5 \text {. The } \\
\text { minimum expected count is } 11.69 .{ }^{\circ} \text { Computed only for a } 2 \times 2 \text { table. 'Chi-square } \\
\text { test, statistical method assessing the relationship between observed and expected } \\
\text { categorical values. }{ }^{2} \text { Symmetric measures determine strength of relationship between } \\
\text { the observed and expected categorical values. }\end{array}$} \\
\hline
\end{tabular}

Table 6 Relationship between non-combined surgery and type of surgery

\begin{tabular}{llll}
\hline Combined surgery & \multicolumn{2}{l}{ Type of surgery } & Total \\
\cline { 2 - 3 } & Shunt* (\%) & Filter** (\%) & \\
\hline Non-combined & $7 \mathrm{I}(64.0)$ & $40(36.0)$ & III \\
Combined & $18(39.1)$ & $28(60.9)$ & 46 \\
Total & $89(56.7)$ & $68(43.3)$ & 157 \\
Chi-square test & & & \\
\hline
\end{tabular}

\begin{tabular}{llll}
\hline & Value & df & $\begin{array}{l}\text { Asymptotic } \\
\text { significance } \\
\text { (2-sided) }\end{array}$ \\
\hline Pearson chi-square & $8.169^{\mathrm{a}}$ & $\mathrm{I}$ & 0.004 \\
Continuity correction $^{\mathrm{b}}$ & 7.189 & $\mathrm{I}$ & 0.007 \\
Likelihood ratio $_{\text {Linear-by-linear association }}$ & 8.148 & $\mathrm{I}$ & 0.004 \\
N of valid cases & 8.117 & $\mathrm{I}$ & 0.004 \\
Symmetric measures $^{2}$ & 157 & & \\
\hline & & & $\mathbf{P}<\mathbf{0 . 0 5}$ \\
\hline Phi & Value & 0.004 \\
Cramer's V & 0.228 & & 0.004 \\
N of valid cases & 0.228 & \\
\hline
\end{tabular}

Notes: *Shunting surgery includes Baerveldt and Ahmed implants. **Filtering surgery includes trabeculectomy and Express. ${ }^{a} 0$ cells $(0.0 \%)$ have expected count $<5$. The minimum expected count is 19.92 . ' $C o m p u t e d$ only for a $2 \times 2$ table. 'Chi-square test, statistical method assessing the relationship between observed and expected categorical values. ${ }^{2}$ Symmetric measures determine strength of relationship between the observed and expected categorical values.

and ptosis as more patients with non-combined surgery also had a statistically significant association with ptosis.

\section{Discussion}

Rates of ptosis can range from $10 \%$ to $44 \%$ after eye surgery, although most tend to resolve without treatment after cataract surgery. ${ }^{1-6}$ The large difference in ptosis rates may be due to temporary aponeurotic ptosis that can occur after surgery compared with permanent aponeurotic ptosis. Permanent aponeurotic ptosis is the most common form of ptosis before and after surgery. It is marked by good levator function of $12-15 \mathrm{~mm}$ and a high or absent lid crease that does not improve. Paris and Quickert ${ }^{4}$ and others ${ }^{13,14}$ have shown that patients with permanent aponeurotic ptosis had disinsertion of the levator palpebrae aponeurosis from the epitarsus and patients with ptosis after surgery had a weak levator

Table 7 The relationship between type of surgery and age

\begin{tabular}{lllll}
\hline $\begin{array}{l}\text { Type of } \\
\text { surgery }\end{array}$ & \multicolumn{2}{l}{ Age categories (years) } & Total \\
\cline { 2 - 4 } & $<\mathbf{6 0}(\%)$ & $\mathbf{6 0 - 6 9 ( \% )}$ & $>\mathbf{7 0}(\%)$ & \\
\hline Filtering* & $17(25.0)$ & $16(23.5)$ & $35(51.5)$ & 68 \\
Shunting** & $22(39.0)$ & $27(30.3)$ & $40(44.9)$ & 89 \\
Total & $39(24.8)$ & $43(27.4)$ & $75(47.8)$ & 157 \\
\hline
\end{tabular}

Notes: *Filtering surgery includes trabeculectomy and Express. **Shunting surgery includes Baerveldt and Ahmed implants. There was no clinical significance between age and type of surgery. 
palpebrae aponeurosis. Several factors have been investigated without conclusive evidence that there is a direct correlation to ptosis. These factors include general anesthesia, lid edema, and use of a bridle suture. Ptosis and the type of lid speculum has been evaluated and believed to play a greater role in patients with smaller palpebral fissures. ${ }^{12}$ Crosby et al ${ }^{12}$ noted that a more rigid speculum can cause greater compression and greatest risk of eyelid malposition involving those with smallest palpebral apertures. Our study did not address the lid speculum secondary to lack of documentation regarding the type of speculum in close to two-thirds of the cases.

The association between patients $<70$ years of age and ptosis was of statistical significance $(P<0.05)$. This was counterintuitive to the expected rates of ptosis in older patients with a weaker or higher likelihood of dehisced levator palpebrae aponeurosis due to involutional changes or history of prior surgery. However, this could also be due to the large amount of bilateral involutional changes seen in those $>70$ years of age. Ptosis became more noticeable in younger patients with less involutional change prior to surgery. Subsequently, new ptosis was likely to be more common in those who are $<70$ years of age, while those who are $>70$ years of age have minimal or less noticeable changes due to involutional ptosis preoperatively.

Patients $>70$ years of age were more likely to have combined surgery $(P<0.05)$ due to the very nature of older patients having cataracts. As expected, a statistically significant $(P<0.05)$ association was present between those who had combined surgery and those without prior surgery since most prior surgeries usually involved cataract surgery. Although combined surgery can be expected in an older age group due to higher prevalance of visually significant cataract in this age group, one could also assume that combined surgery is longer and can result in ptosis due to longer exposure to the lid speculum. However, our results showed that ptosis was more likely to be seen in those $<70$ years of age who had non-combined surgery. Even after excluding prior surgeries that could have previously affected the levator palpebrae aponeurosis, there was a statistically significant $(P<0.05)$ association between ptosis and non-combined surgery.

Naruo-tsuchisaka et $\mathrm{al}^{8}$ have shown that rates of ptosis after trabeculectomy were as high as $19 \%$ with MMC. Although our study did not show statistically significant rates for ptosis with the use of MMC, ptosis was seen in $10.3 \%$ of those with filtering surgery and $22.5 \%$ in those with shunting procedures. The difference was statistically significant $(P<0.05)$ for ptosis to be more likely with shunting surgery compared with filtering surgery. There was also no difference in age group and the type of surgery performed, indicating that there were similar percentages of shunting and filtering surgery per age group. The potential cause of increased ptosis in patients with shunting surgery could be due to the need for increased exposure required during shunting surgery in order to place a glaucoma drainage device $8-10 \mathrm{~mm}$ posterior to the limbus. The need for increased exposure possibly resulted in more pressure on the levator palpebrae aponeurosis by the lid speculum compared with the fornix-based filtering surgery performed in our study.

In our study, variables that showed no clinical significance for ptosis included gender, operated eye, steroid duration, use of MMC, prior surgeries, and duration of surgery. In contrast, those $<70$ years of age appeared to have more non-combined surgery and were more likely to have shunting surgery. These were both statistically significant $(P<0.05)$. All three variables of $<70$ years of age group, non-combined surgery, and shunting surgery showed a statistically significant association $(P<0.05)$ with ptosis. The larger percentage of patients undergoing non-combined surgery in those $<70$ years of age could be due to the current practice pattern or patients without the need to have the cataract removed at the time of glaucoma surgery, which may not be reflected in all practices. The larger number of non-combined, shunting surgery could also be a practice pattern or the desire to perform shunting surgery prior to filtering surgery in more advanced glaucoma, likely to be seen in older patients, and may not be applicable to every practice. However, the statistically significant association between non-combined surgery and ptosis may strengthen the relationship between shunting surgery and ptosis because there was a statistically significant association between noncombined surgery and shunting surgery indicating that noncombined, shunting surgery may contribute to ptosis rather than a possible difference in practice pattern.

Limitations of our study include lack of formal ptosis measurements like those performed in Naruo-tsuchisaka et $\mathrm{al}^{8}$ study with the marginal reflex distance (MRD). Therefore, in our study, ptosis is more likely to be documented in severe cases that can inherently decrease the true number of patients with ptosis, especially in the elderly. It is also difficult to determine the true rate of aponeurotic ptosis in older patients due to the lack of documentation. This may have resulted in the higher number of ptosis in the younger age group. The higher number of ptosis in the younger age group could also reflect the new onset of aponeurotic ptosis evidenced by the documentation of ptosis due to the greater change in eyelid position than those of older patients who may have aponeurotic changes already. Although levator 
function is considered grossly intact when measuring aponeurotic ptosis, there is the possibility that the levator palpebrae muscle is weaker in older patients as well. One could consider the fact that younger patients may increase compression or stress on the eyelid from the speculum secondary to their ability to squeeze their eyelids shut with more strength than older patients. Therefore, the type of speculum, surgery (shunting or filtering), and the pre-, intra-, and postoperative interpalpebral fissures can be measured in further studies to determine if the amount of tension on the eyelids from the speculum also plays a role in aponeurotic ptosis after filtering or shunting surgery.

Crosby et $\mathrm{al}^{12}$ had noted that, smaller palpebral fissures appear to play a role in ptosis and eyelid malposition. However, our study did not address whether patients had small or large palpebral fissures. The palpebral fissure height may also be affected by the preoperative drop regimen, which include medication to dilate the pupil and raise the eyelid. Subsequently, the amount of pressure on the eyelids may also be greater in non-combined surgery compared with combined surgery due to effect of the phenylepherine. Therefore, further prospective studies should be conducted to potentially strengthen the finding of shunting surgery causing more ptosis than filtering surgery by including MRD pre- and postoperatively and vertical palpebral fissure pre-, intra-, and postoperative measurements. Type of surgery and emphasis on intraoperative vertical palpebral fissures measurements after the placement of the speculum can also be measured to determine if greater stretch on eyelids had an association with increased aponeurotic ptosis or changes.

The effect of MMC can also be re-evaluated since some physicians are beginning to use MMC with shunting surgery, and the rate of ptosis of trabeculectomy and MMC in Naruotsuchisaka et $\mathrm{al}^{8}$ study was $19 \%$ compared with $22.5 \%$ for shunting surgery without MMC in our study.

Finally, the limitation of a retrospective study without proper case and control patients limit the utility of the study. Results are limited to the current population and practice patterns in the study. As mentioned above, the pre- and postoperative measurements of MRD and palpebral fissures can provide better results for ptosis after a non-combined shunting or filtering surgery. An age-matched case-control, prospective study measuring changes for ptosis (pre- and postoperative MRD, levator function, and vertical palpebral fissures), use of MMC, type of lid speculum, and non-combined filtering or shunting will likely produce stronger results than our current retrospective study. By conducting a prospective study on non-combined surgery with appropriate ptosis measurements, the comparative data can be more accurate without the variables of practice patterns, improve clarity of rates of new or worsening ptosis in patients $>$ or $<60$ years, and directly compare the rates of new or worsening aponeurotic ptosis between filtering and shunting surgeries.

\section{Conclusion}

There was statistically significant association between shunting surgery being more common than filtering surgery in patients with ptosis without a significant difference in the percentage of shunting or filtering surgery across all our age categories. There was also statistically significant association between ptosis and shunting surgery, regardless of whether the patient had prior surgery. Higher ptosis rates were noted in the younger, $<70$ years age group, that underwent more non-combined surgery, which is typically shorter in duration, though one might expect surgeries of longer duration that include combined surgery, patients with prior surgeries, and older age to have to ptosis.

There was no statistically significant association between the following variables and ptosis: gender, operated eye, steroid duration, use of MMC, prior surgeries, and duration of surgery. The type of speculum could not be analyzed due to lack of documentation.

Our findings of shunting surgery with younger patients and the association with ptosis may be secondary to practice patterns and the desire to preserve filtering surgery for more advanced glaucoma often associated with older patients and to avoid the increased risk of bleb-related infections over the lifetime of the bleb. Furthermore, the association between younger age and ptosis may be due to less involutional changes in younger patients preoperatively, resulting in new or greater changes in ptosis than older patient with pre-existing involutional aponeurotic ptosis prior to surgery. Further studies including the type of surgery; type of lid speculum; pre- and postoperative MRD; pre-, intra-, and postoperative vertical IPF; and pre- and postoperative LF measurements can help evaluate the true rates of aponeurotic ptosis after glaucoma surgery in those who may have had preexisting involutional aponeurotic ptosis before glaucoma surgery.

\section{Acknowledgment}

Patient consent to review medical records was not required since patient data were de-identified and were in compliance with the Boston Medical Center/Boston University School of Medicine Office of Clinical Research Health Insurance 
Portability and Accountability Act (HIPPA) requirements for our retrospective study. Patient identified data were kept in a locked room and destroyed at the end of the study to maintain patient confidentiality.

\section{Disclosure}

The authors report no conflicts of interest in this work.

\section{References}

1. Alpar JJ. Acquired ptosis following cataract and glaucoma surgery. Glaucoma. 1982;4:66-68.

2. Kaplan LJ, Jaffe NS, Clayman HM. Ptosis and cataract surgery. A multivariant computer analysis of a prospective study. Ophthalmology. 1985;92(2):237-242.

3. Patel JI, Blount M, Jones C. Surgical blepharoptosis - the bridle suture factor? Eye (Lond). 2002;16(5):535-537.

4. Paris GL, Quickert MH. Disinsertion of the aponeurosis of the levator palpebrae superioris muscle after cataract extraction. Am J Ophthalmol. 1976;81(3):337-340.

5. Singh SK, Sekhar GC, Gupta S. Etiology of ptosis after cataract surgery. J Cataract Refract Surg. 1997;23(9):1409-1413.
6. Bernardino CR, Rubin PA. Ptosis after cataract surgery. Semin Ophthalmol. 2002;17(3-4):144-148.

7. Hosal BM, Tekeli O, Gürsel E. Eyelid malpositions after cataract surgery. Eur J Ophthalmol. 1998;8(1):12-15.

8. Naruo-tsuchisaka A, Maruyama K, Arimoto G, Goto H. Incidence of postoperative ptosis following trabeculectomy with mitomycin C. J Glaucoma. 2015;24(6):417-420.

9. Song MS, Shin DH, Spoor TC. Incidence of ptosis following trabeculectomy: a comparative study. Korean J Ophthalmol. 1996;10(2):97-103.

10. Ranin EA, Carlson BM. Postoperative diplopia and ptosis. A clinical hypothesis based on the myotoxicity of local anesthetics. Arch Ophthalmol. 1985;103(9):1337-1339.

11. Ropo A, Ruusuvaara P, Nikki P. Ptosis following periocular or general anesthesia in cataract surgery. Acta Ophthalmol (Copenh). 1992;70(2): 262-265.

12. Crosby NJ, Shepherd D, Murray A. Mechanical testing of lid speculae and relationship to postoperative ptosis. Eye (Lond). 2013;27(9): 1098-1101.

13. Baggio E, Ruban JM. Postoperative ptosis: etiopathogenesis, clinical analysis, and therapeutic management. Apropos of a series of 43 cases. J Fr Ophtalmol. 1998;21(5):361-373.

14. Parsa FD, Wolff DR, Parsa NN, Elahia EE. Upper eyelid ptosis repair after cataract extraction and the importance of Hering's test. Plast Reconstr Surg. 2001;108(6):1527-1536; discussion 1537-1538.
Clinical Ophthalmology

\section{Publish your work in this journal}

Clinical Ophthalmology is an international, peer-reviewed journa covering all subspecialties within ophthalmology. Key topics include: Optometry; Visual science; Pharmacology and drug therapy in eye diseases; Basic Sciences; Primary and Secondary eye care; Patient Safety and Quality of Care Improvements. This journal is indexed on

Submit your manuscript here: http://www.dovepress.com/clinical-ophthalmology-journal

\section{Dovepress}

PubMed Central and CAS, and is the official journal of The Society of Clinical Ophthalmology (SCO). The manuscript management system is completely online and includes a very quick and fair peer-review system, which is all easy to use. Visit http://www.dovepress.com/ testimonials.php to read real quotes from published authors. 